\title{
Cyberbullying and Bullying: Impact on Psychological Symptoms and Well-Being
}

\section{Marina Carvalho, et al. [full author details at the end of the article]}

Accepted: 10 July 2020/Published online: 31 July 2020

(C) Springer Nature B.V. 2020

\begin{abstract}
Related, but with different impacts on psychological symptoms and well-being, bullying and cyberbullying have been the subject of numerous studies. The present study analysed the associations between cyberbullying and bullying, specifically: 1) gender, school grade and age associations with cyberbullying and bullying; 2) the impact of cyberbullying and bullying on psychological, social and contextual symptoms and well-being according to cyberbullying involvement, and 3) a combined bullying context was compared to single bullying contexts and to non-involvement for psychological, social and contextual factors, and well-being, among a cross-sectional and randomly assigned sample based on the 2014 Health Behaviour in School-aged Children Portuguese Study, a World Health Organization collaborative study (HBSC/ WHO). Composed by 6026 adolescents (47.7\% male), aged between 10 and 19.92 years old $(M=13.77 ; S D=1.68)$, in the 6 th, 8 th, and 10th grades, results showed that $10.9 \%$ of the participants reported being involved in cyberbullying, as cybervictims, cyberbullies or cyberbully-victims, and $47.9 \%$ in bullying. Most of the cybervictims reported being involved as victims and bully-victims in bullying; cyberbullies as bully-victims in bullying, and most of the cyberbully-victims reported having the same role in bullying. Frequently, cybervictims were females and most of the cyberbullies and cyberbully-victims were males. No significant associations were found for age and for Body Mass Index. Comparisons between groups, based on the participants' role in cyberbullying, showed significant differences for substances use, emotional symptoms, school context, fights and friends. Further comparisons (according to participant's role, not involved, or involved in single or combined bullying) evidenced the cumulative effect of combined bullying. In conclusion, given the different characteristics and impact of cyberbullying on cybervictims, cyberbullies and cyberbully-victims, is crucial to consider the interrelations between the groups and focus on a more engaging perspective, based on an ecological intervention model. Results will be discussed from a public policy perspective.
\end{abstract}

Keywords Cyberbullying $\cdot$ Bullying $\cdot$ Psychological symptoms $\cdot$ Well-being $\cdot$ Adolescents

Inseparably related, sharing in their definition the pattern of aggressive and intentional behavior repeated over time, in interpersonal relations characterized by an imbalance of 
power (Olweus 1996; Olweus 1997), bullying and cyberbullying have been the target of numerous studies, mainly focused on demonstrating their negative impacts on mental health, especially of the victims (e.g., AUTHORS 2014a, 2014b; AUTHORS 2017a; Fahy et al. 2016; Fridh et al. 2015; Hamm et al. 2015; AUTHORS 2014c; Sampasa-Kanyinga 2017; Vieno et al. 2015), and on school, in attachment, and subsequent academic achievement (Schneider et al. 2012).

Still insufficient are the studies focusing on the factors associated with the single or multiple role as victims, bullies or bully-victims, in these two forms of violence, distinguished by perpetuation through the electronic context that define cyberbullying (Kowalski et al. 2014).

According to Vaillancourt and colleagues (2016), when cyberbullying and bullying are compared, the negative impacts of cyberbullying tend to be worse. Translated into higher absenteeism and low school performance, as well as increased depression, anxiety and self-esteem (Giumetti and Kowalski 2015), cyberbullying shows a strong and negative effect on adolescents' health and wellbeing (Vaillancourt et al. 2016). A study of the relationships between emotional problems and cyberbullying (controlling for the effects of bullying), has shown that cybervictims and bullying victims, present unique emotional symptoms, characteristics of this specific type of involvement (Gini et al. 2017). On the other hand, the results obtained in the study developed by Landstedt and Persson (2014), showed that somatic and depressive symptoms, appeared correlated to any type of bullying. In a systematic review performed by Bottino and colleagues in 2015, cybervictims and cyberbullies report more somatic, emotional and social problems, and less security feelings at school. In this systematic review, cyberbullying also demonstrated a strong association with substance use, and depressive symptoms.

But are psychological distress, emotional symptoms, and mental health problems, the only characteristics that bullying victims and cybervictims share?

Several studies report that bullies and bullying victims, both in traditional and cyberbullying, have significant differences in age (Inchley et al. 2016), psychological symptoms (Cosma et al. 2017), friendship relationships (Erginoz et al. 2015), depressive symptoms (Du et al. 2018), and alcohol consumption (Peleg-Oren et al. 2010). Other studies report that offenders and bullies are older boys (Inchley et al. 2016), taller (AUTHORS 2017b), substances users (Gaete et al. 2017), prone to violent behaviours (Nixon 2014) or other conduct or prosocial problems (Skrzypiec et al. 2012) and also better accepted and with a larger involvement and security feelings at school and more facilitated peer relationships (AUTHORS 2017a).

According to the HBSC 2010 survey results (Currie et al. 2012), bullying tends to decrease by age in both males and females and in most of the countries. This consistent decrease in bullying behaviors along the years and specific country differences may be explained by cultural aspects (Molcho et al. 2009). More recently, for bullying, results have confirmed the age and gender pattern and, for cyberbullying, although it tends to decrease by age, no gender pattern was found (Inchley et al. 2016). At a national level, Matos et al. (2015) confirmed the existence of gender differences in both traditional bullying and cyberbullying and, also, a decrease by age.

One specific question that arises is the role of body weight and body mass index (BMI) in bullying involvement, in both traditional bullying and cyberbullying. Janssen et al. (2004), studied the relationships between overweight and obesity with bullying 
and concluded that overweight and obese children were more likely to be both victims and perpetrators of bullying behaviours, compared to their normal-weight peers. In 2011, Brixval et al. also studied the relationship between weight status and exposure to bullying in the Danish cross-sectional sample of the HBSC and found a direct association between overweight and obesity with bullying in both boys and girls, taking into account the role of body image. More recently, in a study performed with the main goal of analysing the longitudinal relationships between bullying with BMI and obesity, Mamun et al. (2013) found that both males and females who were victimized were at greater risk of higher BNI and obesity in adulthood in particular when overweight. Also, in a meta-analysis on the association between weight and bullying, van Geel et al. (2014) found that both overweight and obese youths were more likely to be victims of bullying, independently of gender.

However, studies about the role of weight and BMI in cyberbullying are still scarce. According to Lee et al. (2018), overweight in childhood and adolescence is linked to several physical health and mental health problems but, also, to the likelihood of becoming a victim of bullying. In their study, authors found that BMI was related to physical and mental health problems and that victimization mediated the relationship between BMI and psychological symptoms in both traditional bulling and cyberbullying.

Theoretical models on behaviour problems, including bullying and cyberbullying, show the influence of individual, social/contextual, and family variables on the development of bullying and cyberbullying problems (Georgiou and Fanti 2010). According to an integrated developmental perspective (Postigo et al. 2013), the interactions between these factors explain the individual differences which are found and identify shared and specific characteristics of bullies and victims.

Based on the relevance of the analysis of bullying and cyberbullying' outcomes for the psychological functioning of each of the involved, and on the need of more evidences about the cumulative effect of the exposure both to bullying and cyberbullying, the present study had the main goal of analysing the association between cyberbullying and bullying among school-aged children. Specifically: 1) Gender, school grade and age associations with cyberbullying and bullying were analysed;2) The impact of cyberbullying and bullying on psychological, social and contextual symptoms and well-being was studied according to cyberbullying involvement (as a victim, a bully or a bully-victim), and 3) A combined bullying context was compared to single bullying contexts and to non-involvement for psychological, social and contextual factors, and well-being.

\section{Method}

\subsection{Participants}

Six thousand and twenty-six adolescents, $47.7 \%$ male, aged between 10 and 20 years old (although the study is carried out with adolescents, young adults attending the 10th grade were also included), mean age of 13.77 years old, in the 6th (35.8\%), 8th (39.1\%), and 10th school year (25.1\%), randomly assigned from national schools 
representing all the country, participated in the 2014 wave of the stratified Portuguese sample of the HBSC.

The demographic characteristics of the participants are represented in Table 1. Other details on other demographic characteristics can be found in Matos et al. (2015).

\subsubsection{Measures}

The HBSC questionnaire (Currie et al. 2012; Inchley et al. 2016) was used, as part of the Portuguese membership in the International Study.

The questionnaire collects information about the health status of adolescents of school-aged children in their life contexts and includes a sociodemographic data section and further sections about school context, alcohol, tobacco and drugs use, violence, physical activity and hobbies, nutrition, security, sedentary behaviour, sexual behaviour, psychosocial health, general symptoms, family context, social relationships and social support. Each questionnaire requires about $55 \mathrm{~min}$ to be completed. Further information about the study and its methods, used through all the HBSC waves, is fully described elsewhere (Roberts et al. 2009). Data about reliability and validity of the items is presented by Roberson and Renshaw (2017).

In the present work due to the focus of the study were considered the variables that literature has surfaced as potentially related to the bullying/ cyberbullying phenomenon, therefore only variables related to bullying and cyberbullying, substances use (smoke tobacco, alcohol use and drug use), emotional problems (fear, sadness and rejection feelings), weight, height and BMI (defined as weight in kilograms divided by the square of height in meters), school context (liking school), social relationships (acceptance from peers, friends help, feeling safe at school, peers get together, good friends in real life, virtual friends, time spent with friends after school and at evening, and making friends), physical fighting and well-being were used (see Table 2). To

Table 1 Demographic characteristics of the sample

\begin{tabular}{llllllll}
\hline & $\mathrm{N}$ & $\%$ & $\mathrm{M}$ & $\mathrm{SD}$ & Range & Skewness & Kurtosis \\
\hline Gender & & & & & & \\
$\quad$ Boys & 2872 & 47.7 & & & & \\
$\quad$ Girls & 3154 & 52.3 & & & & \\
School Grade & & & & & & \\
$\quad$ 6th year & 2157 & 35.8 & & & & \\
$\quad$ 8th year & 2358 & 39.1 & & & & \\
10th year & 1511 & 25.1 & & & & \\
Region & & & & & & \\
$\quad$ North & 2506 & 41.6 & & & & \\
$\quad$ Lisbon and Vale do Tejo & 1217 & 20.2 & & & & \\
$\quad$ Centre & 1031 & 17.1 & & & & \\
$\quad$ Alentejo & 755 & 12.5 & & & & \\
$\quad$ Algarve & 517 & 8.6 & & & & \\
Age & 6026 & 100 & 13.77 & 1.68 & $10-20$ & .202 & \\
\hline
\end{tabular}


measure bullying and cyberbullying, the survey has a number of mandatory items and, also, a number of national -based items. In this specific study, we used the question that is used nationally to evaluate cyberbullying trend since 2010 .

Specifically, bullying and cyberbullying were assessed through questions one and two, respectively, referring to the participants' involvement in bullying situations (being bullied/being a bully) in school context or online in a one week/month period. The two questions involving bullying ("How often have you taken part in bullying another student at school in the past couple of months?" and "How often have you been bullied at school in the past couple of months?"), were transformed into a single variable, according to the participants' involvement, with four categories: a) No, I have never been involved, b) Yes, as victim, C) Yes, as a bully, d) Yes, as a victim and as a bully). The question about cyberbullying asked if "Have you ever been involved in situations of provocation through new technologies?". Participants were also included in one of four categories, according to their exposure to cyberbullying situations: a) No, I have never been involved, b) Yes, as a cyber-victim, C) Yes, as a cyberbully, d) Yes, as a cyberbully-victim.".

Table 2 Items used and range

\begin{tabular}{|c|c|}
\hline Items & Range \\
\hline Smoke Tobacco & 1-4 (every day/don't smoke) * \\
\hline Alcohol use & $1-5$ (every day/never) $*$ \\
\hline Drug use & $1-4$ (never/regularly) \\
\hline Fear & $1-5$ (almost every day/rarely or never) $*$ \\
\hline Sadness & $1-5$ (almost every day/rarely or never) $*$ \\
\hline Rejection feelings & $1-5$ (strongly agree/strongly disagree) $*$ \\
\hline Weight & Body mass weight (in kilos) \\
\hline Height & Body mass height (in cms) \\
\hline Liking school & $1-4($ A lot - not at all $) *$ \\
\hline Acceptance from peers & $1-5$ (strongly agree/strongly disagree) $*$ \\
\hline Friends help & $1-5$ (strongly agree/strongly disagree) $*$ \\
\hline Feeling safe at school & $1-5$ (always - never) $*$ \\
\hline Peers get togheter & $1-5$ (strongly agree/strongly disagree) $*$ \\
\hline Good friends in real life & $1-4$ (none -3 or more $)$ \\
\hline Virtual Friends & $1-4$ (none -3 or more) \\
\hline Time spent with friends after school & $0-6$ (0 days -6 days a week $)$ \\
\hline Time spent with friends in the evening & 0-7 (0 days -7 days a week) \\
\hline Making new friends & $1-4$ (very easy - very hard) $*$ \\
\hline Physical fighting & $1-5$ (never involved/four times or more) \\
\hline Well-being & $1-4$ (very happy/very unhappy) * \\
\hline Cyberbullying & $\begin{array}{l}\text { 0-4 (never involved; cybervictim; cyberbully; } \\
\text { cyberbully-victim) }\end{array}$ \\
\hline \multirow[t]{2}{*}{ Bullying } & As a bully, $1-5$ (never to several times a week) \\
\hline & As bullied, $1-5$ (never to several times a week) \\
\hline
\end{tabular}

* Reverted items 
Finally, one last transformation, based on the results of the cyberbullying and the new bullying variable, was made to compute a new variable related to single or combined bullying involvement (in bullying and cyberbullying), also with four categories: a) Only in Bullying; b) Only in Cyberbullying; c) Both in Bullying and Cyberbullying; and d) Not Involved.

\subsubsection{Procedure}

The public schools that took part on the sampling process, were randomly selected from the national schools list and stratified by the five educational regions. In each school, a random selection of classes was carried out, and the questionnaire was administered in the computer room, online, and assisted by the NT teachers, after parental consent and the students' informed consent to their volunteer and anonymous participation in the study.

In Portugal, HBSC research was submitted to the Ethical Committee of Oporto Medical School and was developed after the approval of the Monitoring of Inquiries in School Context/Ministry of Education and National Data Protection System. Details on the procedures for data collection in the HBSC Study in Portugal can be consulted in Matos, Simões, Camacho, Reis and Equipa Aventura Social (2015) and the methods used to gather these data are further described in detail in Currie et al. (2009).

\subsubsection{Statistical Analysis}

SPSS 21.0 for Windows (SPSS, Chicago IL, USA) was used to carry out Qui-square tests to analyse the associations between the variables. Ordinal variables were transformed, and z scores were calculated to carry out factorial ANOVAS and MANOVAS tests to compare groups. In the tables, adjusted standardized residuals superior to 1.9 are presented in bold.

\section{Results}

\subsection{Prevalence of Cyberbullying and Bullying in the 2014 Portuguese HBSC Sample}

Results showed that $10.9 \%$ of the participants reported being involved in cyberbullying $(N=590 ; 5366$ valid cases) and that $47.9 \%$ of the participants reported being involved in bullying $(N=2615$; 5464 valid cases) in a one week/month basis, in either one of the roles: as a victim, as a bully, and/or as a bully-victim.

Table 3 shows the results of the descriptive classification of the participants according to their involvement.

Although $52.1 \%$ and $89.1 \%$ of the participants reported not being involved in bullying and cyberbullying, respectively, results also showed that, when combining the involvement in bullying and in cyberbullying, $8.5 \%$ of the participants $(N=454)$ reported being involved in both bullying contexts, $41.8 \%$ of the participants $(N=2244)$ reported being involved in only one of the bullying 
Table 3 Classification of the participants based on their involvement

\begin{tabular}{|c|c|c|c|c|}
\hline & $\begin{array}{l}\text { Cybervictims } \\
(N=297)\end{array}$ & $\begin{array}{l}\text { Cyberbullies } \\
(N=109)\end{array}$ & $\begin{array}{l}\text { Cyberbully-victims } \\
(N=184)\end{array}$ & $\begin{array}{l}\text { Not involved in cyberbullying } \\
(4776)\end{array}$ \\
\hline Victims & 90 & 17 & 25 & 769 \\
\hline$(N=901)$ & $(30.3 \%)$ & $(15 \%)$ & $(13.6 \%)$ & $(16.1 \%)$ \\
\hline Bullies & 16 & 29 & 20 & 422 \\
\hline$(N=487)$ & $(5.4 \%)$ & $(26.6 \%)$ & $(10.9 \%)$ & $(4.2 \%)$ \\
\hline Provocative victims & 111 & 49 & 97 & 917 \\
\hline$(N=1174)$ & $(37.4 \%)$ & $45 \%$ & $(52.7 \%)$ & $(19.2 \%)$ \\
\hline Not involved in bullying & 80 & 14 & 42 & 2668 \\
\hline$(N=2804)$ & $(26.9 \%)$ & $(12.8 \%)$ & $(22.8 \%)$ & $(55.9 \%)$ \\
\hline
\end{tabular}

contexts, and $49.7 \%$ of the participants $(N=2668)$ reported not being involved in any of the bullying contexts.

\subsection{Associations between Cyberbullying and Bullying}

A significant association was found between cyberbullying and bullying $(\chi 2(4)=$ $51.73 ; p=.0005)$. Most of the cybervictims reported being victims and bully-victims in bullying; cyberbullies reported being bully-victims in bullying, and most of the cyberbully-victims reported having the same role in bullying (see Table 4).

\subsection{Associations between Gender and School Grade with Cyberbullying and Bullying}

Table 5 shows the results of the associations between cyberbullying and bullying involvement with gender and school grade.

A significant association between cyberbullying and gender was found, $\chi 2(2)=$ 44.97; $p=.0005$. More than half of the cybervictims were females and most of the

Table 4 Associations between bullying and cyberbullying

\begin{tabular}{|c|c|c|c|c|c|c|c|}
\hline & \multicolumn{6}{|c|}{ Bullying } & \multirow[t]{3}{*}{$\chi^{2}$} \\
\hline & \multicolumn{2}{|c|}{ Victims } & \multicolumn{2}{|c|}{ Bullies } & \multicolumn{2}{|c|}{ Provocative-victims } & \\
\hline & $\mathrm{N}$ & $\%$ & $\mathrm{~N}$ & $\%$ & $\mathrm{~N}$ & $\%$ & \\
\hline Cyberbullying & & & & & & & $51.73 * * *$ \\
\hline Cybervictims & 90 & 41.5 & 16 & 7.4 & 111 & 51.2 & \\
\hline Cyberbullies & 17 & 17.9 & 29 & 30.5 & 49 & 51.6 & \\
\hline Cyberbully-Victims & 25 & 17.6 & 20 & 14.1 & 97 & 68.3 & \\
\hline
\end{tabular}

$* * * p \leq .001$ 
Table 5 Associations between gender and school grade with bullying and cyberbullying

\begin{tabular}{|c|c|c|c|c|c|c|c|}
\hline & \multicolumn{3}{|c|}{ Male } & \multicolumn{3}{|c|}{ Female } & \multirow[t]{2}{*}{$\chi^{2}$} \\
\hline & $\mathrm{N}$ & \multicolumn{2}{|l|}{$\%$} & $\mathrm{~N}$ & \multicolumn{2}{|l|}{$\%$} & \\
\hline \multicolumn{7}{|l|}{ Cyberbullying } & \multirow[t]{4}{*}{$44.97 * * * *$} \\
\hline Cybervictims & 80 & 36.9 & & 137 & 63. & & \\
\hline Cyberbullies & 72 & 75.8 & & 23 & 24. & & \\
\hline Cyberbully-victims & 85 & 59.9 & & 57 & 40. & & \\
\hline \multicolumn{7}{|l|}{ Bullying } & \multirow[t]{4}{*}{$13.75^{* * * *}$} \\
\hline Victims & 51 & 38.6 & & 81 & 61. & & \\
\hline Bullies & 37 & 56.9 & & 28 & 43. & & \\
\hline \multirow[t]{3}{*}{ Provocative-victims } & 149 & 58 & & 108 & 42 & & \\
\hline & \multicolumn{2}{|c|}{ 6th Grade } & \multicolumn{2}{|c|}{ 8th Grade } & \multicolumn{2}{|c|}{ 10th Grade } & \multirow[t]{2}{*}{$\chi^{2}$} \\
\hline & $\mathrm{N}$ & $\%$ & $\mathrm{~N}$ & $\%$ & $\mathrm{~N}$ & $\%$ & \\
\hline \multicolumn{7}{|l|}{ Cyberbullying } & \multirow[t]{4}{*}{3.58} \\
\hline Cybervictims & 67 & 30.9 & 87 & 40.1 & 63 & 29 & \\
\hline Cyberbullies & 28 & 29.5 & 46 & 48.4 & 21 & 22.1 & \\
\hline Cyberbullies-victims & 45 & 31.7 & 53 & 37.3 & 44 & 31 & \\
\hline \multicolumn{7}{|l|}{ Bullying } & \multirow[t]{4}{*}{$10.02 *$} \\
\hline Victims & 29 & 22 & 55 & 41.6 & 48 & 36.4 & \\
\hline Bullies & 22 & 33.8 & 24 & 36.9 & 19 & 29.2 & \\
\hline Provocative-victims & 89 & 34.6 & 107 & 41.6 & 61 & 23.7 & \\
\hline
\end{tabular}

$* * * \mathrm{p} \leq .001 ; * p \leq .05$

cyberbullies and cyberbully-victims were males. No significant associations between cyberbullying and school grade were found, $p>.05$.

For bullying, the obtained pattern for gender was similar, $\chi 2(2)=44.97 ; p=.0005$. Once again, more than half of the victims were females, and more than half of the bullies were males. But in this case, a significant association was found with school grade, $\chi 2(4)=10.02 ; p=.04$. More victims were in the 8 th and 10 th grade and more bully-victims were in the 8 th grade.

\subsection{Associations between Age and BMI with Cyberbullying and Bullying}

Comparisons between groups, according to the participants' involvement on bullying and/or cyberbullying were performed through Factorial Anovas [3*3]. Age and BMI were introduced as dependent variables.

No significant main or interaction effects of and cyberbullying were found for age, $F$ bullying $(2,445)=2.018, F$ cyberbullying $(2,445)=.589$, and $F$ bullying * cyberbullying (4, $445)=.259, p>.05$. The same pattern was obtained for BMI, which showed no significant main or interaction effects from or cyberbullying, $F$ bullying $(2,438)=.065$, $F$ cyberbullying $(2,438)=.354$, and $F$ bullying * cyberbullying $(4,438)=1.47, p>.05$.

When studied independently, weight and height presented the same pattern, $\mathrm{p}>.05$. 


\subsection{Comparisons between Groups, According to Cyberbullying and Bullying Involvement, for Risk Behaviours, Emotional Symptoms, Social Relationships, and Well-Being}

Comparisons between groups, according to the participants' involvement on bullying and cyberbullying for substances use, physical fights, school context, social relationships, emotional symptoms and well-being were analyzed through multivariate and univariate variance analyses.

For emotional symptoms (fear, sadness, rejection feelings and peers' acceptance), a significant multivariate effect of bullying was found, Wilks' $\lambda=.954, F(8,884)=2.63$, $p=.007, \eta^{2}=.023$. The main effect of cyberbullying and the interaction effect of cyberbullying * bullying was not significant, $p>.05$. Subsequent univariate analyses showed significant differences between groups for peers' acceptance, $F$ bullying (2, $445)=5.35, p=.005, \eta^{2}=.023$, and fear, $F$ bullying $(2,445)=4.43, p=.012, \eta^{2}=.020$. Post-hoc tests, using Scheffe method, showed that bullies reported more acceptance from peers compared to victims and bully-victims who, in turn, reported more fear, compared to bullies.

When analysing substances use (tobacco, alcohol, and drugs use), significant multivariate main effects of cyberbullying, Wilks' $\lambda=.952, F(6,594)=2.45, p=.024$, $\eta^{2}=.024$, and bullying, Wilks' $\lambda=.953, \mathrm{~F}(6,594)=2.413, p=.026, \eta^{2}=.024$, were obtained. The interaction effect of cyberbullying * bullying was not significant, $p>.05$. Further univariate analyses revealed significant differences for alcohol use related to cyberbullying, $F$ cyberbullying $(2,299)=2.73, p=.06, \eta^{2}=.018$, and significant differences for tobacco, $F$ bullying $(2,299)=4.34, p=.014, \eta^{2}=.028$, and drugs use, $F$ bullying $(2,299)=5.61, p=.004, \eta^{2}=.036$, related to bullying. Post-hoc analyses, using the Scheffe method, revealed that cyberbully-victims reported using more alcohol compared to cybervictims and that, in bullying, bullies reported using more tobacco and drugs, compared to victims and bully-victims.

In the school context (liking school, friends help, get together and feeling safe), only a significant multivariate main effect of cyberbullying was found, Wilks' $\lambda=.963, F$ $(8,876)=2.057, p=.037, \eta^{2}=.024$. The main effect of bullying and the interaction effect between cyberbullying * bullying was not significant, $p>.05$. Further univariate analyses evidenced a significant difference for liking school, $F$ cyberbullying $(2,441)=$ $3.748, p=.024, \eta^{2}=.017$. Multiple comparisons between cyberbullying groups, using the Scheffe method, revealed that cyberbullies reported liking less of the school compared to cybervictims.

Social relationships (good friends in real life, virtual friends, being with friends after school and in the evening, and making friends easily) were also analysed through multivariate variance analysis, which demonstrated only a significant multivariate main effect of bullying, Wilks' $\lambda=.948, F(10,754)=2.059, p=.026, \eta^{2}=.027$. The main effect of cyberbullying and the interaction effect between cyberbullying * bullying was not significant, $p>.05$. Univariate analysis showed significant differences in time spent with friends in the evening, $F$ bullying $(2,381)=4.551, p=.011, \eta^{2}=.023$. The analysis of the differences between groups means, through Scheffe method, showed that bullies and bully-victims reported spending more days a week with friends in the evening, compared to victims. 
Finally, for physical fighting, significant main effects of cyberbullying, $F$ cyberbullying $(2,440)=7.266, p=.0001, \eta^{2}=.032$, and bullying were found, $F$ bullying $(2,440)=$ $7.689, p=.001, \eta^{2}=.034$. Once again, the interaction effect was not significant, $p>.05$. Post-hoc analyses, using the Scheffe method, revealed that cyberbullies reported a higher level of involvement in fights, compared to cyberbully-victims which, in turn, reported the same compared to cybervictims; on the other hand, in bullying, bullies and bully-victims also reported a higher level of involvement in fights.

No significant main or interaction multivariate effects were found for well-being, $p>.05$. Table 6 resumes the obtained information about groups' comparisons.

In general, results show that although involvement in fights has a similar pattern between cyberbullying and bullying, there are specific factors involved in each of the bullying contexts. Emotional symptoms are more relevant in bullying, substances use is relevant in both forms of bullying although alcohol use is related to cyberbullying and tobacco and drugs use is related to bullying; finally, liking school is specifically related to cyberbullying and being with friends in the evenings specifically related to bullying.

\subsection{Comparisons between Groups, According to their Involvement in Bullying Contexts}

In order to understand the cumulative effect of combined forms of bullying (traditional and cyberbullying), four groups were constituted: one group, composed of 2668 participants, reported not being involved at all in any form of bullying; the second group, composed of 2108 participants reported being involved only in bullying; the third group, composed of 136 participants, reported being only involved in cyberbullying; and, finally, the fourth group, composed of 454 participants, reported being involved in bullying and in cyberbullying.

Comparisons between groups for demographic variables showed significant associations with gender and school grade, and significant differences for age. The Bullying group was composed of more males and the Not Involved group was composed of more females $\left(\chi^{2}(3)=39.375 ; p=.0005\right)$. The Bullying group had more participants from the 6th and 8th grades and the Not Involved group had more participants from the

Table 6 Multiple comparisons between groups

\begin{tabular}{llc}
\hline & Cyberbullying & Bullying \\
\hline Acceptance from peers & & $\mathrm{B}>\mathrm{V}, \mathrm{VP}$ \\
Fear & & $\mathrm{V}, \mathrm{PV}>\mathrm{B}$ \\
Tobacco use & $\mathrm{CBV}>\mathrm{CV}$ & $\mathrm{B}>\mathrm{V}, \mathrm{VP}$ \\
Alcohol use & & $\mathrm{B}>\mathrm{V}, \mathrm{VP}$ \\
$\begin{array}{l}\text { Drugs use } \\
\text { Liking school }\end{array}$ & $\mathrm{CB}<\mathrm{CV}$ & $\mathrm{B}, \mathrm{PV}>\mathrm{V}$ \\
Being with friends in the evening & & $\mathrm{B}, \mathrm{PV}>\mathrm{V}$ \\
Physical fights & $\mathrm{CB}>\mathrm{CBV}>\mathrm{CV}$ & \\
\hline
\end{tabular}

Legend: $\mathrm{B}=$ Bullies; $\mathrm{V}=$ Victims; $\mathrm{PV}=$ Provocative-victims; $\mathrm{CB}=$ Cyberbullies; $\mathrm{CV}=$ Cybervictims; $\mathrm{CBV}=$ Cyberbully-victims 
10th grade, $(\chi 2(6)=136.82 ; p=.0005)$. Finally, participants in Not Involved and Bullying groups were younger than participants in the combined Cyber and Bullying group who, in turn, were younger than participants in the Cyberbullying only group ( $F$ $(3,5362)=38.65 ; p=.0005)$.

Further comparisons between groups, for substances use, emotional symptoms, school context and social relationships, analyzed through univariate variance analyses, showed significant differences for all the dependent variables (see Table 7).

Results of post-hoc analyses, using the Scheffe method, are presented in Table 8. All together, these results evidence the existence of general factors related to both bullying contexts but also, specific factors related differentially to each of the forms. For most of the studied variables, the combination of the involvement in bullying and cyberbullying has more harmful effects at emotional, social, and behavioural levels.

\section{Discussion}

Studies on the impact and factors related to bullying and cyberbullying have been the focus of increasing attention over the years. Due to the impact of bullying and cyberbullying on psychological, school and social functioning, the main goal of the present study was to analyse the associations between cyberbullying and bullying. Specifically, we aimed at analysing gender, age and school grade associations, as well

Table 7 Comparisons between groups, according to single versus combined involvement in bullying

\begin{tabular}{|c|c|c|c|c|c|c|c|c|c|}
\hline & \multicolumn{2}{|c|}{ Not involved } & \multicolumn{2}{|c|}{ Bullying } & \multicolumn{2}{|c|}{ Cyberbullying } & \multicolumn{2}{|c|}{ Bullying \& Cyberbullying } & \multirow[t]{2}{*}{$\mathrm{F}$} \\
\hline & M & $\mathrm{SD}$ & M & $\mathrm{SD}$ & M & SD & M & $\mathrm{SD}$ & \\
\hline Tobacco & -.07 & 1.02 & -.01 & .97 & .40 & 1.52 & .45 & 1.60 & $40.59 * * *$ \\
\hline Alcohol use & .07 & .88 & .01 & .97 & .53 & 1.20 & .50 & 1.53 & $54.35 * * *$ \\
\hline Drugs use & -.08 & .72 & .00 & 1.01 & .18 & 1.49 & .38 & 1.76 & $20.28 * * *$ \\
\hline Liking school & .09 & .94 & -.07 & .99 & -.13 & .95 & -.35 & 1.17 & $31.69 * * *$ \\
\hline Friends help & .18 & .91 & -.17 & 1.05 & .08 & 1.01 & -.23 & 1.13 & $52.17 * * *$ \\
\hline Get together & .09 & .95 & -.09 & 1.02 & -.03 & 1.00 & -.18 & 1.15 & $18.21 * * *$ \\
\hline Feeling safe & .20 & .89 & -.18 & 1.02 & -.03 & .96 & -.39 & 1.17 & $85.51 * * *$ \\
\hline Rejection & -.17 & .92 & .08 & 1.00 & -.11 & .87 & .27 & 1.09 & $41.82 * * *$ \\
\hline Fear & -.17 & .80 & .09 & 1.06 & .34 & 1.28 & .47 & 1.29 & $74.21 * * *$ \\
\hline Sadness & -.19 & .79 & .12 & 1.08 & .44 & 1.26 & .56 & 1.33 & $103.29 * * *$ \\
\hline Physical fights & -.27 & .62 & .15 & 1.09 & .01 & 1.07 & .84 & 1.53 & $212.09 * * *$ \\
\hline Real life friends & .07 & .92 & -.03 & 1.01 & -.02 & 1.04 & -.23 & 1.28 & $12.09 * * *$ \\
\hline Virtual friends & -.09 & .93 & .02 & 1.00 & .02 & .98 & .39 & 1.26 & $28.30 * * *$ \\
\hline Friends after school & -.03 & .99 & .01 & 1.00 & .03 & .98 & .13 & .99 & $2.79 *$ \\
\hline Friends evening & -.11 & .84 & .01 & 1.02 & .22 & 1.19 & .48 & 1.39 & $44.09 * * *$ \\
\hline Making friends & .06 & .95 & -.06 & 1.02 & -.19 & 1.00 & -.06 & 1.16 & $7.37 * * *$ \\
\hline Well-being & .17 & .91 & -.13 & 1.01 & -.30 & 1.01 & -.33 & 1.20 & $53.12 * * *$ \\
\hline
\end{tabular}

$* * * \mathrm{p} \leq .001 ; * \mathrm{p} \leq .05$ 
Table 8 Results of multiple comparisons between groups

\begin{tabular}{ll} 
Tobacco use & $\mathrm{C} \& \mathrm{~B}, \mathrm{C}>\mathrm{B}, \mathrm{NI}$ \\
Alcohol use & $\mathrm{C} \& \mathrm{~B}, \mathrm{C}>\mathrm{B}, \mathrm{NI}$ \\
Drugs use & $\mathrm{C} \& \mathrm{~B}, \mathrm{C}>\mathrm{B}>\mathrm{NI}$ \\
Fear & $\mathrm{C} \& \mathrm{~B}, \mathrm{C}>\mathrm{B}>\mathrm{NI}$ \\
Sadness & $\mathrm{C} \& \mathrm{~B}, \mathrm{C}>\mathrm{B}>\mathrm{NI}$ \\
Rejection feelings & $\mathrm{C} \& \mathrm{~B}>\mathrm{B}>\mathrm{C}, \mathrm{NI}$ \\
Friends help & $\mathrm{NI}, \mathrm{C}>\mathrm{B}, \mathrm{C} \& \mathrm{~B}$ \\
Acceptance from peers & $\mathrm{NI}, \mathrm{C}>\mathrm{B}, \mathrm{C} \& \mathrm{~B}$ \\
Liking school & $\mathrm{NI}, \mathrm{B}>\mathrm{C}>\mathrm{C} \& \mathrm{~B}$ \\
Peers get together at school & $\mathrm{NI}>\mathrm{C} \& \mathrm{~B}$ \\
Feeling safe at school & $\mathrm{NI}>\mathrm{B}, \mathrm{C}>\mathrm{C} \& \mathrm{~B}$ \\
Virtual friends & $\mathrm{C} \& \mathrm{~B}>\mathrm{B}, \mathrm{C}, \mathrm{NI}$ \\
Good friends in real life & $\mathrm{C} \& \mathrm{~B}<\mathrm{B}, \mathrm{C}, \mathrm{NI}$ \\
Making friends & $\mathrm{NI}>\mathrm{C}$ \\
Evenings with friends & $\mathrm{C} \& \mathrm{~B}>\mathrm{C}>\mathrm{B}, \mathrm{NI}$ \\
Physical fights & $\mathrm{C} \& \mathrm{~B}>\mathrm{C}, \mathrm{B}>\mathrm{NI}$ \\
Well-being & $\mathrm{NI}>\mathrm{B}, \mathrm{C}>\mathrm{C} \& \mathrm{~B}$ \\
\hline
\end{tabular}

Legend: $\mathrm{B}=$ Bullying; $\mathrm{CB}=$ Cyberbullying; $\mathrm{C} \& \mathrm{~B}=$ Combined Bullying and Cyberbullying; $\mathrm{NI}=\mathrm{Not}$ Involved

as the effects of single and combined bullying contexts on psychological symptoms and well-being,

Results have shown that, so far (2014), the cyberbullying phenomena in Portugal is far less frequent compared to bullying. About $1 / 10$ of the participants reported being involved in cyberbullying whereas about half of the participants reported being involved in bullying, in a one week/month basis, in either one of the roles: as a victim, as a bully, and/or as a bully-victim. Due to the different measuring instruments used, along with the operationalization of the bullying construct, a heterogeneity of prevalence is found in the studies (Menesini and Salmivalli 2017).

The results have also showed that a small part of the adolescents involved in cyberbullying were also involved in bullying ( $8.5 \%$ of the participants reported being involved in both bullying contexts - bullying and cyberbullying), with the two bullying contexts being highly associated. Waasdorp and Bradshaw (2015) and Hase et al. (2015), in two overlap studies between bullying and cyberbullying, corroborate that cyberbullying often occurs with other forms of bullying, with a frequent overlap between cybervictims and bullying victims.

It seems like cyberbullying allows an increased participation of girls in the (cyber) bullying process in the role of cyberbullies. Opposite to what happens in bullying, there were no gender differences on being a cyberbully. Still, no significant associations between cyberbullying and school grade were found, opposite to what happened in bullying, contradicting our hypothesis based on bullying HBSC international data (Inchley et al. 2016), that younger boys would be the most likely bullying victims and cybervictims, and older boys would play the offender role in both bullying forms. 
Also opposite to other studies (DeSmet et al. 2014) and to our assumption that bullying victims and cybervictims would be overweight or obese and the bullies and cyberbullies would be taller, no significant associations with BMI were found, nor considering the BMI index or weight and height independently. Although is possible that this result may be related to the measurement of these constructs, it also suggests that the alleged advantage of appearing physically taller in the bully process is vanishing, as was surfaced before in other studies using data from HBSC in previous waves (AUTHORS 2017b).

When considering emotional symptoms, and congruent with our hypotheses, results surfaced that bullies reported having more acceptance from peers compared to victims and bully-victims who, in turn, reported more fear, compared to bullies. This fact was already highlighted before and calls for action once the "bright side" of popularity tends to promote a bully attitude that, in consequence, tends to increase fear and sense of insecurity in others, which may lead to e.g. substance use (e.g. Gaete et al. 2017) or to a trajectory to a bully status in later grades.

Regarding substances use, results revealed that cyberbully-victims reported using more alcohol compared to cybervictims while, in bullying, bullies reported using more tobacco and drugs, compared to victims and bully-victims, validating our assumption, based on the study of the author Gaete et al. (2017). In previous studies, alcohol was also part of this cluster, especially in bullies (AUTHORS 2017a, 2017b) suggesting that this result needs further comprehensive studies to better understand its role and associated factors.

In a previous study carried out by AUTHORS (2017b), bullies reported being more involved in school, which leds us to assume that this result could also extend to cyberbullies. However, in the present study, bullying and cyberbullying seems to be associated to poorer school attitudes, especially for cyberbullies. Regarding social life, it was interesting to confirm that bullies and bully-victims reported spending more days a week with friends in the evening, compared to victims, while there were no significant differences in cyberbullying, as if social life was transferred to screen time. This finding is somehow contradictory with previous findings, suggesting that screen social relations are an extension of one's "real life" (Kuntsche et al. 2009). But if this is true for social relationships, it is not so true for abusive social relations. However, cyberbullies and bullies reported a higher level of involvement in fights, thus confirming a similar pattern between cyberbullying and bullying.

When the four groups were composed (not involved; involved in cyberbullying; involved in bullying and involved in both cyber and bullying) results evidenced specific factors related differentially to each of the forms and, for most of the studied variables, the combination of the involvement in bullying and cyberbullying has more harmful effects at emotional, social, and behavioural levels, surfacing a continuity with cumulative effects when interpersonal relationships become negative and abusive. Although is possible that these results may reflect the existing demographic differences between the groups, it is true that these differences were, in general, expected and reflect the natural trajectories of violence. Future studies should consider a deeper analysis of the demographics of these groups, as well as the within group differences in the participants' roles as victims, bullies or bully-victims. 
From one side it was surfaced, as said before, a continuity, which means the existence of a "same underlying process" which allows someone to include and appreciate violence and abuse in interpersonal relationships. In these situations, cyberbullying will allow the abusers to have another social context to abuse - the screen and online media and, in short, more time where bullying is allowed, as a continuation from home and not only in school. This continuity has also surfaces in the distant attitude of both cyberbullies and bullies from school.

From another perspective, there are new features, such as girls being able to cyberbully (when in real life they may not have the physical capacities) and alcohol intake (when alcohol acquisition and use is easier in non-public contexts due to its illegal consumption in minors in Portugal). Drugs are also illegal, but their use is lower and associated to a more deviant trajectory (Hays and Ellickson 1996).

Cyberbullying gives bullying other "possibilities" and it is plausible that it is still a growing phenomenon, which calls / calling to urgent and increased public policies and action in both school and families' settings. Being a rather new phenomenon, related to a "native born digital" generation, cyberbullying requires the young people's social participation (in the definition of this phenomena, associated features, ways to limit it, and its consequences) which is the natural path to prevent both forms of bullying and to promote a friendlier and healthier way of relating with peers.

In summary, the results obtained in this study demonstrated a progression through the different forms of involvement in bullying and cyberbullying that appears to be similar to the progression of violence in general, from overt to covert, from physical for psychological, throughout development. In this sense, cyberbullying can be assumed as a covert form of peer violence, which calls for more differentiated strategies. The existence of factors common to both forms of bullying and specific factors for each of them was also a result that seems very important. Both forms of involvement related to substances consumption and emotional symptoms, which were even more frequent in the combined involvement in bullying and cyberbullying. On the other hand, the non-involvement in any of the forms of bullying, as the involvement in cyberbullying, was associated with a set of social factors that involve the ability to help, the relationship with the school and the ease of making friends. If, in the case of young people without involvement, these characteristics can present a protective function, in cyberbullying contexts these characteristics can contribute to maintain the problem. Thus, non-involvement was discriminated from cyberbullying only based on emotional well-being. Despite the retroactive relationship between the two variables, remains unanswered if it is the level of emotional well-being that protects young people from involving in bullying and cyberbullying situations or if, alternatively, emotional well-being is promoted by non-involvement.

In conclusion, the present study adds to previous research a broader perspective and a more comprehensive view of the different factors that may be involved in the explanation of the individual differences bullying and cyberbullying, demonstrating the need of considering the existence of different factors, at different levels, that may interact to increase the risk of bullying and/ or cyberbullying involvement. 


\subsection{Limitations}

Although our results are important and, in part, consistent with those of most previous studies, the study's limitations need to be considered when interpreting the results. On the one hand, the nature of the sample, cross-sectional, does not allow the establishment and analyses of causal relationships between the variables and the study of the stability of their impact in the analyzed groups. Second, the evaluation of bullying and cyberbullying was made from a basic set of items that refers to the involvement of the participants in each of the forms of bullying and that does not account for other relevant aspects such as its content and related actions and, also, frequency. Third, the study addressed a large set of variables which may be seen as too much considering the scope of these studies. However, the literature about risk and protection factors tells us that the interactions between several risk and protection factors interaction may contribute to explain in depth these individual differences.

\subsection{Future Orientations}

Future studies should assess different aspects of bullying in order to control for these limitations and include prospective longitudinal designs to examine the cyberbullying stability and lifespan trajectories. Also, future studies should analyse in depth the interactions between individual, social and contextual factors involved in cyberbullying onset, maintenance and modification and, at an international level, may assess these specificities in traditional and cyberbullying using multilevel analysis techniques.

Nevertheless, the current results were quite clear surfacing that:

- $\quad$-Most of the cyberbullying actors reported being somehow involved in bullying as well.

- $\quad$-There is a gendered distribution of adolescents among cybervictims, cyberbullies or cyberbully-victims, no matter in what age group.

Cyberbullying actors, according to their role in cyberbullying, showed significant differences for substances use, emotional symptoms, school context, fights and relationship with friends.

- $\quad$-There is a cumulative effect of diverse forms of bullying/cyberbullying

Public policies, especially in the domain of Education and Health are to be alerted by these results pointing out that if the bullying phenomenon is able to undermine adolescent's health and well-being and preventing at least some of them from growing within a positive and warmth peer social interaction context cyberbullying opens the opportunity to new, more uncertain undermining procedures. Furthermore, preventive and promotional strategies both to bullying and cyberbullying are to be well fitted to adolescents' different profiles, because they are different and differently affected by both phenomena. It is also crucial to consider the interrelations between the different groups/clusters regarding bullying/cyberbullying involvement and to focus on a more engaging perspective, based on a participatory-ecological intervention model.

There is thus an urgent need of parents and teachers in depth training for screening and intervention, and school policies increasing awareness, stimulating zero tolerance and including adolescents' active engagement identifying associated problems and designing preventive strategies with peer's active involvement. 


\section{References}

AUTHORS (2014a). Emotional problems and substance use in adolescents: gender and age differences and psychosocial determinants. Public Health Frontier, 3(2), 28-34. Ddoi: https://doi.org/10.5963 /PHF0302002.

AUTHORS. (2014b). Psychosocial Correlates of Violence over 8 Years. Asian Journal of Humanities and Social Studies, 2(2), 219-229.

AUTHORS. (2014c). Psychosocial determinants of mental health and risk behaviours in adolescents. Global Journal of Health Science, 6(4), 22-35. https://doi.org/10.5539/gjhs.v6n4p22.

AUTHORS (2017a). Bullies, victims and provocative victims in context: Discriminant factors in a Portuguese adolescent sample. European Scientific Journal, 13(20), 23-36. doi: 10.19044/esj.2017.v13n20p23

AUTHORS (2017b). The taller the better? Psychobiological influences on bullying behaviour among Portuguese adolescents. International Journal of Pediatrics and Neonatal Health, 1 (3), 65-73. doi: 10.25141/2572-4355-2017-3.0065

Bottino, S. M., Bottino, C. M., Regina, C. G., Correia, A. V., \& Ribeiro, W. S. (2015). Cyberbullying and adolescent mental health: Systematic review. Cadernos de Saude Publica, 31(3), 463-475.

Brixval, C. S., Rayce, S. L. B., Rasmussen, M., Holstein, B. E., \& Due, P. (2011). Overweight, body image and bullying-an epidemiological study of 11- to 15-years olds. European Journal of Public Health, 22(1), 126-130. https://doi.org/10.1093/eurpub/ckr010.

Cosma, A., Whitehead, R., Neville, F., Currie, D., \& Inchley, J. (2017). Trends in bullying victimization in Scottish adolescents 1994-2014: changing associations with mental well-being. International Journal of Public Health, 62(6), 639-646. https://doi.org/10.1007/s00038-017-0965-6.

Currie, C., Nic Gabhainn, S., \& Godeau, E. (2009). International HBSC Network Coordinating Committee. The Health Behaviour in School-aged Children: WHO Collaborative Cross-National (HBSC) study: Origins, concept, history and development 1982-2008. International Journal of Public Health, 54(Suppl 2), 131-139. https://doi.org/10.1007/s00038-009-5404-x.

Currie, C., Zanotti, C., Morgan, A., Currie, D., de Looze, M., Roberts, C. ... \& Barnekow, V. (Eds.) (2012). Social determinants of health and well-being among young people. Health Behaviour in School-aged Children (HBSC) study: international report from the 2009/2010 survey. Copenhagen: WHO Regional Office for Europe (Health Policy for Children and Adolescents, No. 6).

DeSmet, A., Deforche, B., Hublet, A., Tanghe, A., Stremersch, E., \& De Bourdeaudhuij, I. (2014). Traditional and cyberbullying victimization as correlates of psychosocial distress and barriers to a healthy lifestyle among severely obese adolescents. A matched case-control study on prevalence and results from a crosssectional study. BMC Public Health, 14, 224. https://doi.org/10.1186/1471-2458-14-224.

Du, C., DeGuisto, K., Albright, J., \& Alrehaili, S. (2018). Peer Support as a Mediator between Bullying Victimization and Depression. International Journal of Psychological Studies, 10(1), 59-68. https://doi. org/10.5539/ijps.v10n1p59.

Erginoz, E., Alikasifoglu, M., Ercan, O., Uysal, O., Alp, Z., Ocak, S., et al. (2015). The Role of Parental, School, and Peer Factors in Adolescent Bullying Involvement: Results From the Turkish HBSC 2005/2006 Study. Asia Pacific Journal of Public Health, 27(2), NP1591-NP1603. https://doi. org/10.1177/1010539512473144.

Fahy, A. E., Stansfeld, S. A., Smuk, M., Smith, N. R., Cummins, S., \& Clark, C. (2016). Longitudinal associations between cyberbullying involvement and adolescent mental health. Journal of Adolescent Health, 59(5), 502-509. https://doi.org/10.1016/j.jadohealth.2016.06.006.

Fridh, M., Lindström, M., \& Rosvall, M. (2015). Subjective health complaints in adolescent victims of cyber harassment: Moderation through support from parents/friends - a Swedish population-based study. BMC Public Health, 23(15), 949. https://doi.org/10.1186/s12889-015-2239-7.

Gaete, J., Tornero, B., Valenzuela, D., Rojas-Barahona, C. A., Salmivalli, C., Valenzuela, E., \& Araya, R. (2017). Substance Use among Adolescents Involved in Bullying: A Cross-Sectional Multilevel Study. Frontiers in psychology, 8, 1056. https://doi.org/10.3389/fpsyg.2017.01056.

Georgiou, S. N., \& Fanti, K. A. (2010). A transactional model of bullying and victimization. Social Psychology of Education: An International Journal, 13(3), 295-311. https://doi.org/10.1007/s11218010-9116-0.

Gini, G., Card, N. A., \& Pozzoli, T. (2017). A meta-analysis of the differential relations of traditional and cyber-victimization with internalizing problems. Aggressive Behavior, 43(6), eprint online first. Doi: https://doi.org/10.1002/ab.21742

Giumetti, G. W., \& Kowalski, R. M. (2015). Cyberbullying matters: examining the incremental impact of cyberbullying on outcomes over and above traditional bullying. In R. Navarro, S. Yubero, \& E. Larranaga 
(Eds.), Cyberbullying across the globe: gender, family, and mental health (pp. 117-130). New York: Springer.

Hamm, M. P., Newton, A. S., Chisholm, A., Shulhan, J., Milne, A., Sundar, P., et al. (2015). Prevalence and effect of cyberbullying on children and young people: A scoping review of social media studies. Journal of American Medical Association Pediatrics, 169(8), 770-777. https://doi.org/10.1001 /jamapediatrics.2015.0944.

Hays, R. D., \& Ellickson, P. L. (1996). Associations beetween drug use and deviant behavior in teenagers. Addictive Behaviors, 21, 291-302.

Hase, C. N., Goldberg, S. B., Smith, D., Stuck, A., \& Campain, J. (2015). Impacts of Traditional Bullying and Cyberbullying on the Mental Health of Middle and High School Students. Psychology in the Schools, 52, 607-617. https://doi.org/10.1002/pits.21841.

Inchley, J. C., Currie, D. B., Young, T., Samdal, O., Torsheim, T., Augustson, L., et al. (Eds.). (2016). Growing up unequal: gender and socioeconomic differences in young people's health and well-being: Health Behaviour in School-aged Children (HBSC) study: international report from the 2013/2014 survey. (Health Policy for Children and Adolescents; No. 7). Denmark: WHO Regional Office for Europe.

Janssen, I., Craig, W. M., Boyce, W. F., \& Pickett, W. (2004). Associations Between Overweight and Obesity With Bullying Behaviors in School-Aged Children. Pediatrics, 113(5), 1187-1194. https://doi. org/10.1542/peds.113.5.1187.

Kowalski, R. M., Giumetti, G. W., Schroeder, A. N., \& Lattanner, M. R. (2014). Bullying in the Digital Age: A Critical Review and Meta-Analysis of Cyberbullying Research Among Youth. Psychological Bulletin, 140(4), 1073-1137. https://doi.org/10.1037/a0035618.

Kuntsche, E., Simons-Morton, B., ter Bogt, T., Sánchez Queija, I., Muñoz Tinoco, V., Gaspar de Matos, M., Santinello, M., Lenzi, M., \& The HBSC Peer Culture Focus Group. (2009). Electronic media communication with friends from 2002 to 2006 and links to face to-face contacts in adolescence: an HBSC study in 31 European and North American countries and regions. International Journal of Public Health, 54, 243-250. https://doi.org/10.1007/s00038-009-5416-6.

Landstedt, E., \& Persson, S. (2014). Bullying, cyberbullying, and mental health in young people. Scandinavian Journal of Public Health, 42(4), 393-399. https://doi.org/10.1177/1403494814525004.

Lee, B., Jeong, S., \& Roh, M. (2018). Association between body mass index and health outcomes among adolescents: The mediating role of traditional and cyber bullying victimization. BMC Public Health., 18, 674. https://doi.org/10.1186/s12889-018-5390-0.

Mamun, A. A., O’Callaghan, M. J., Williams, G. M., \& Najman, J. M. (2013). Adolescents bullying and young adults body mass index and obesity: A longitudinal study. International Journal of Obesity, 37, 1140-1146.

Matos, M. G., Simões, C., Camacho, I., Reis, M., \& Equipa Aventura Social (2015) A saúde dos adolescentes Portugueses em tempos de recessão - Dados nacionais do estudo HBSC de 2014 [The health of Portuguese adolescents in times of recession - National data from the 2014 HBSC study]. Lisboa: IHMT/UNL, FMH/UL. ISBN: 978-989-98,346-1-3.

Menesini, E., \& Salmivalli, C. (2017). Bullying in schools: the state of knowledge and effective interventions. Psychology, Health \& Medicine, 22(1), 240-253. https://doi.org/10.1080/13548506.2017.1279740.

Molcho, M., Craig, W., Due, P., Pickett, W., Harel-Fisch, Y., \& Overpeck, M. (2009). Cross-national time trends in bullying behaviour 1994-2006: Findings from Europe and North America. International Journal of Public Health, 54(2), 225-234.

Nixon, C. L. (2014). Current perspectives: the impact of cyberbullying on adolescent health. Adolescent Health, Medicine and Therapeutics, 5, 143-158. https://doi.org/10.2147/AHMT.S36456.

Olweus, D. (1996). Bullying at School Knowledge Base and an Effective Intervention Program. Annals of the New York Academy of Science, 794(1), 265-276. https://doi.org/10.1111/j.1749-6632.1996.tb32527.x.

Olweus, D. (1997). Bully/victim problems in school: Facts and intervention. European Journal of Psychology of Education, 12(4), 495-510.

Peleg-Oren, N., Cardenas, G. A., Comerford, M., \& Galea, S. (2010). An Association Between Bullying Behaviors and Alcohol Use Among Middle School Students. The Journal of Early Adolescence, 32(6), 761-775. https://doi.org/10.1177/0272431610387144.

Postigo, S., González, R., Montoya, I., \& Ordoñez, A. (2013). Theoretical proposals in bullying research: A review. Anales de Psicología, 29(2), 413-425. https://doi.org/10.6018/analesps.29.2.148251.

Roberson, A. J., \& Renshaw, T. L. (2017). Structural validity of the HBSC bullying measure: Self-report rating scales of youth victimization and perpetration behaviour. Journal of Psychoeducational Assessment, 1-16. https://doi.org/10.1177/0734282917696932. 
Roberts, C., Freeman, J., Samdal, O., Schnohr, C. W., de Looze, M. E., Gabhainn, N., et al. (2009). The Health Behaviour in School-aged Children (HBSC) study: methodological developments and current tensions. International Journal of Public Health, 54, S140-S150. https://doi.org/10.1007/s00038-0095405-9.

Sampasa-Kanyinga, H. (2017). Co-occurring cyberbullying and school bullying victimization and associations with mental health problems among Canadian middle and high school students. Violence and Victims, 32(4), 671-687. https://doi.org/10.1891/0886-6708.VV-D-16-00031.

Schneider, S. K., O’Donnell, L., Stueve, A., \& Coulter, R. W. S. (2012). Cyberbullying, School Bullying, and Psychological Distress: A Regional Census of High School Students. American Journal of Public Health, $(102,1), 171-177$.

Skrzypiec, G. K., Slee, P. T., Askell-Williams, H., \& Lawson, M. J. (2012). Associations between types of involvement in bullying, friendships and mental health status. Emotional and Behavioural Difficulties, 17(3-4), 259-272. https://doi.org/10.1080/13632752.2012.704312.

Vaillancourt, T., Faris, R., \& Mishna, F. (2016). Cyberbullying in Children and Youth: Implications for Health and Clinical Practice. Canadian journal of Psychiatry, 62(6), 368-373. https://doi.org/10.1177 /0706743716684791.

van Geel, M., Vedder, P., \& Tanilon, J. (2014). Are overweight and obese youths more often bullied by their peers? A meta-analysis on the relation between weight status and bullying. International Journal of Obesity, 38, 1263-1267.

Vieno, A., Gini, G., Lenzi, M., Pozzoli, T., Canale, N., \& Santinello, M. (2015). Cybervictimization and somatic and psychological symptoms among Italian middle school students. European Journal of Public Health, 25(3), 433-437. https://doi.org/10.1093/eurpub/cku191.

Waasdorp, T., \& Bradshaw, C. P. (2015). The Overlap Between Cyberbullying and Traditional Bullying. Journal of Adolescent Health, 56(5), 483-488. https://doi.org/10.1016/j.jadohealth.2014.12.002.

Publisher's Note Springer Nature remains neutral with regard to jurisdictional claims in published maps and institutional affiliations.

\section{Affiliations}

\section{Marina Carvalho ${ }^{1}$. Cátia Branquinho ${ }^{2}$. Margarida Gaspar de Matos ${ }^{2}$}

\section{Marina Carvalho}

marina.carvalho@ismat.pt; marina.carvalho@hbsc.org

1 ISMAT Centre for Research in Psychology; Psychiatry Department of CHUA; ISAMB, University of Lisbon, Lisbon, Portugal

2 Faculty of Human Movement University of Lisbon; ISAMB/University of Lisbon; APPSYci/ISPA, Lisbon, Portugal 